\title{
Altered lipoproteins in patients with systemic lupus erythematosus are associated with augmented oxidative stress: a potential role in atherosclerosis
}

Jin Kyun Park ${ }^{1,2}$, Jae-Yong Kim³ ${ }^{3}$ Jin Young Moon ${ }^{2}$, Eun Young Ahn², Eun Young Lee², Eun Bong Lee², Kyung-Hyun $\mathrm{Cho}^{3}$ and Yeong Wook Song ${ }^{1,2,4^{*}}$

\begin{abstract}
Background: To examine the structural and oxidative properties of lipoproteins from patients with systemic lupus erythematosus (SLE).

Methods: The lipid profiles of 35 SLE patients and 15 healthy controls (HCs) were compared. Oxidation status, susceptibility to oxidation, and structural integrity of low-density lipoprotein (LDL) were determined by measuring malondialdehyde (MDA), de novo formation of conjugated dienes in the presence of $\mathrm{CuSO}_{4}$, and mobility on gel electrophoresis, respectively. In vitro foam cell formation and the oxidative potential in zebrafish embryos were examined.

Results: LDL levels in SLE patients and HCs were similar $(p=0.277)$. LDL from SLE patients was more fragmented than that from HCs. In addition, LDL from SLE patients was more oxidized than LDL from HCs $(p<0.001)$ and more susceptible to de novo oxidation $(p<0.001)$ in vitro. THP-1 cells engulfed more LDL from SLE patients than LDL from HCs $(p<0.001)$. LDL from SLE patients, which was injected into zebrafish embryos, induced a higher degree of oxidation and a higher mortality than LDL from HCs (both $p<0.001$ ). The survival of embryos treated with oxidized LDL was significantly better in the presence of $\mathrm{HDL}_{3}$ from $\mathrm{HCs}$ than that from SLE patients (all $p<0.001$ ).
\end{abstract}

Conclusions: Lipoproteins from SLE patients exhibited greater oxidative potential, which might contribute to accelerated atherosclerosis in SLE.

Keywords: Atherosclerosis, Oxidation, Lipoproteins, LDL, Systemic lupus erythematosus

\section{Background}

Systemic lupus erythematosus (SLE) is a chronic inflammatory multisystem disease mediated by immune cell activation and autoantibody production [1]. Patients with SLE carry an increased risk (up to 17-fold) of developing a cardiovascular $(\mathrm{CV})$ disease $[2,3]$. Although traditional risk factors for $\mathrm{CV}$ disease are more prevalent in patients with

\footnotetext{
* Correspondence: ysong@snu.ac.kr

'Department of Molecular Medicine and Biopharmaceutical Sciences, Graduate School of Convergence Science and Technology, and College of Medicine, Medical Research Center, Seoul National University, Seoul, Republic of Korea

${ }^{2}$ Division of Rheumatology, Department of Internal Medicine, Seoul National University Hospital, Seoul, Republic of Korea

Full list of author information is available at the end of the article
}

SLE than in the general population [4-7], they do not solely account for the increased $\mathrm{CV}$ risk observed in these patients $[8,9]$. As an example, a significant reduction of total cholesterol levels with atorvastatin failed to halt progression of atherosclerosis or to decrease inflammatory markers such as C-reactive protein (CRP) in SLE patients $[10,11]$. Therefore, SLE with chronic inflammation increases CV risk by influencing traditional and nontraditional pro- and anti-atherogenic factors.

High-density lipoprotein (HDL) is crucial in the prevention of the atherosclerosis. It prevents oxidation of low-density lipoprotein (LDL) and removes reactive oxygen species from LDL $[12,13]$. Dysfunctional HDL has been linked to an increased risk of atherosclerosis during 
chronic inflammation [14, 15]. Indeed, half of women with SLE have high levels of pro-inflammatory HDL, which fails to protect LDL from damaging oxidation [16, 17]. This oxidation of lipoproteins might be further potentiated by reactive oxygen species, which are generated excessively within the inflamed tissue of SLE patients. Subsequent accumulation of oxidized LDL (oxLDL) induces apoptosis of vascular smooth muscle cells and accelerates cellular senescence [18]. In addition, oxLDL is engulfed by monocytes, which then produce inflammatory cytokines and transform into foam cells, thereby contributing to the development of atherosclerosis $[19,20]$. Taken together, the altered structural and functional properties of lipoproteins might contribute to accelerated atherosclerosis associated with SLE, possibly via interaction with immune cells [5].

Since oxidation of lipoproteins is a crucial step for atherosclerosis, this study aimed to investigate the oxidative properties of lipoproteins from SLE patients both in vitro and in vivo.

\section{Methods \\ Patients}

A total of 35 patients fulfilling the 1997 American College of Rheumatology classification criteria for SLE [21] were recruited at Seoul National University Hospital. Disease activity at the time of blood sampling was determined using the SLE disease activity index 2000 (SLEDAI-2 K) [22]. Fifteen individuals without other comorbidities were included as healthy controls (HCs).

\section{Sample preparation and lipoprotein isolation}

Blood was obtained after overnight fasting, and serum was separated by low-speed centrifugation and stored at $-80{ }^{\circ} \mathrm{C}$ until analysis. The storage time did not differ between SLE and HC samples (109.6 \pm 69.2 days vs. 88.4 \pm 8.7 days, $p=0.40$ ). Lipoproteins, including very lowdensity lipoprotein (density $<1.019 \mathrm{~g} / \mathrm{mL}$ ), LDL (density $1.019-1.063 \mathrm{~g} / \mathrm{mL}$ ), $\mathrm{HDL}_{2}$ (density $1.064-1.125 \mathrm{~g} / \mathrm{mL}$ ), and $\mathrm{HDL}_{3}$ (density $1.126-1.225 \mathrm{~g} / \mathrm{mL}$ ) were isolated from serum by sequential ultracentrifugation as previously described [23]. Briefly, the density was adjusted by addition of $\mathrm{NaCl}$ and $\mathrm{NaBr}$ and samples were centrifuged for 24 hours at $10{ }^{\circ} \mathrm{C}$ at $100,000 \mathrm{~g}$ using a Himac CP-90 $\alpha$ (Hitachi, Tokyo, Japan).

To generate oxLDL, $300 \mu \mathrm{g}$ of LDL that had been purified from healthy controls was incubated with $10 \mu \mathrm{M} \mathrm{CuSO}_{4}$ for 4 hours at $37^{\circ} \mathrm{C}$.

\section{Analysis of lipoproteins}

Total cholesterol and triglyceride (TG) levels were measured using commercially available kits (Diagnostics; Osaka, Japan). LDL cholesterol levels were calculated using the Friedewald formula. The protein content of the lipoproteins was measured using the Lowry protein assay as previously described [24].

\section{Copper-mediated oxidation of lipoproteins}

The amount of oxidized species in lipoproteins was quantified by measuring malondialdehyde (MDA) levels using the thiobarbituric acid reactive substance method as previously described [25].

To investigate the susceptibility to copper-mediated de novo oxidation, $300 \mu \mathrm{g}$ of LDL, which was isolated from SLE or $\mathrm{HC}$, was incubated with $5 \mu \mathrm{M} \mathrm{CuSO}_{4}$ for 3 hours. During the incubation, the formation of conjugated dienes was determined by measuring the absorbance at $234 \mathrm{~nm}$ at $37{ }^{\circ} \mathrm{C}$ using a Beckman DU 800 spectrophotometer (Beckman Coulter, Fullerton, CA, USA), equipped with a MultiTemp III thermocirculator (Amersham Biosciences, Uppsala, Sweden) [24].

\section{Electrophoresis and Western blot analysis}

Apolipoprotein/lipoprotein composition was compared by sodium dodecyl sulfate-polyacrylamide gel electrophoresis (SDS-PAGE). Identical amounts of $\mathrm{HDL}_{2}$, $\mathrm{HDL}_{3}$, and LDL (3 $\mu \mathrm{g}$ of total protein), which had been pooled from 19 SLE patients or $8 \mathrm{HCs}$, were loaded into the lanes (Additional file 1: Table S1 and Figure S1).

For Western blot analysis, proteins were transferred onto a nitrocellulose membrane and the blots were incubated with goat anti-human apoA-I antibody (clone\# ab7613, Abcam, Cambridge, UK) and then with anti-goat IgG horseradish peroxidase conjugate (Sigma-Aldrich, St. Louis, MO, USA). The detection was performed by a chemiluminescent method (ECL, Amersham Biosciences, Uppsala, Sweden).

For semi-quantitative analysis of lipoproteins, images of SDS-PAGE gels and films were scanned using Gel Doc $^{\circ}$ XR (Bio-Rad, Hercules, CA, USA) and the intensity of bands was analyzed using Quantity One software (version 4.5.2; Bio-Rad, Hercules, CA, USA).

\section{Cholesteryl ester (CE) transfer assay}

Recombinant HDL (rHDL) containing apoA-I was synthesized in the presence of $\left[{ }^{3} \mathrm{H}\right]$-cholesteryl oleate (TRK886; $3.5 \mu \mathrm{Ci} / \mathrm{mg}$ of apoA-I; GE Healthcare, Chicago, IL, USA). $\mathrm{HDL}_{3}(20 \mu \mathrm{L}, 2 \mathrm{mg} / \mathrm{mL}),\left[{ }^{3} \mathrm{H}\right]-\mathrm{rHDL}$, and human LDL served as a cholesteryl ester (CE) transfer protein, a CE donor, and a CE acceptor, respectively. After incubation at $37{ }^{\circ} \mathrm{C}$, the amount of $\mathrm{CE}$ acceptor was measured using scintillation counting and the percentage transfer of $\left[{ }^{3} \mathrm{H}\right]-$ CE from rHDL to LDL was calculated as previously described $[26,27]$.

\section{Paraoxonase assay}

Serum paraoxonase activity was determined by measuring the hydrolysis of paraoxon to p-nitrophenol and 
diethyl phosphates in the presence of paraoxonase as a catalyst. Briefly, $10 \mu \mathrm{L}$ of diluted serum was added to $200 \mu \mathrm{L}$ of paraoxon-ethyl (Sigma D-9286; Sigma-Aldrich, St. Louis, MO, USA) in a buffer containing $90 \mathrm{mM}$ Tris- $\mathrm{HCl}, 3.6 \mathrm{mM} \mathrm{NaCl}$, and $2 \mathrm{mM} \mathrm{CaCl}_{2}(\mathrm{pH}$ 8.5). The production of p-nitrophenol at $37^{\circ} \mathrm{C}$ was determined by measuring the absorbance at $405 \mathrm{~nm}$ using a Microplate reader (Bio-Rad, Hercules, CA, USA). A paraoxonase activity of $1 \mathrm{U} / \mathrm{L}$ was defined as the formation of $1 \mu \mathrm{mol}$ of p-nitrophenol per minute [28].

\section{Phagocytosis of LDL by macrophages}

LDL isolated from SLE patients or HCs was incubated with a fluorescent cholesterol derivative (22-(N-7-nitrobenz-2oxa-1,3-diazol-4-yl) amino-23, 24-bisnor-5-cholen-3-ol [NBD-cholesterol], Molecular Probes, Eugene, OR, USA, $\mathrm{N}-1148 ; 70 \mu \mathrm{g}$ of NBD-cholesterol/mg of apoA-I). THP-1 cells were then differentiated into macrophages in the presence of phorbol myristate acetate and incubated with $50 \mu \mathrm{L}$ of labeled LDL (1 mg of protein/mL in PBS) for 48 hours at $37{ }^{\circ} \mathrm{C}$ in a humidified incubator. After washing with PBS, cells were fixed for $10 \mathrm{~min}$ in $4 \%$ paraformaldehyde and photographed under a Nikon Eclipse TE2000 microscope (Tokyo, Japan) at $\times 600$ magnification (excitation wavelength $=488 \mathrm{~nm}$; emission wavelength $=535 \mathrm{~nm}$ ). NBD positive area was measured.

\section{Senescence-associated (SA)- $\beta$-galactosidase activity}

Cultured fibroblasts were used at passages 11-15 (approximately 40\% confluence). Cells were incubated with lipoprotein fractions $(0.1 \mathrm{mg} / \mathrm{mL})$, fixed with $3 \%$ paraformaldehyde for $5 \mathrm{~min}$, washed with PBS, and incubated with senescence-associated (SA)- $\beta$-galactosidase staining solution (40 $\mathrm{mM}$ citric acid, phosphate [pH 6.0], $5 \mathrm{mM}$ potassium ferrocyanide, $5 \mathrm{mM}$ potassium ferricyanide, $150 \mathrm{mM} \mathrm{NaCl}, 2 \mathrm{mM} \mathrm{MgCl}$, and $1 \mathrm{mg} / \mathrm{mL}$ 5-bromo-4-chloro-3-indolyl-X-galactosidase) for 16 hours at $37{ }^{\circ} \mathrm{C}$. The cells were then observed under a light microscope, and the percentage of blue cells was calculated.

\section{Microinjection of zebrafish embryos}

All experimental procedures and maintenance of zebrafish (Linebrass, $\mathrm{AB}$ strain) were approved by the Committee of Animal Care and Use at Yeungnam University (Gyeongsan, Korea). Embryos (obtained 4 hours after fertilization) were microinjected with PBS or lipoproteins using a pneumatic picopump (PV820, World Precision Instruments; Sarasota, FL, USA). The embryos were then observed for 48 hours under a stereomicroscope (Motic SM 168; Hong Kong) and imaged using a Moticam 2300 CCD camera.

\section{Measurement of oxidation in vivo}

After injection, the fluorescence intensity (excitation = $588 \mathrm{~nm}$ and emission $=605 \mathrm{~nm}$ ) of oxidized dihydroethidium (DHE; Sigma-Aldrich, St. Louis, MO, USA) in the embryos was examined under a Nikon Eclipse TE2000 microscope (Tokyo, Japan) and quantified using Image Proplus software (version 4.5.1.22; Media Cybernetics, Bethesda, MD, USA).

\section{Statistical analysis}

Results are expressed as the mean \pm standard deviation (SD). Differences between the two groups were assessed using the Mann-Whitney $U$ test or $t$ test as appropriate. All reported $p$ values were two-sided, and $p$ values $<0.05$ were considered significant. All statistical analyses were performed using GraphPad Prism 5.01 (GraphPad Software Inc.; La Jolla, CA, USA).

\section{Results}

\section{Patient characteristics}

The mean age of the SLE patients was $40.6 \pm 11.7$ years, and the majority were female (97.1\%). Mean disease duration was $12.1 \pm 7.6$ years, and the mean SLEDAI$2 \mathrm{~K}$ was $4.26 \pm 4.24$. The majority of patients were taking glucocorticoids (mean prednisolone equivalent dose, $7.8 \mathrm{mg} / \mathrm{d}$ ) and hydroxychloroquine at the time of blood sampling. Only few patients were taking an additional immunosuppressant such as azathioprine or methotrexate (Table 1).

\section{Comparison of serum lipid profiles between SLE patients and $\mathrm{HCs}$}

There was no difference in total cholesterol levels between SLE patients and HCs $(190.1 \pm 54.1 \mathrm{mg} / \mathrm{dL}$ vs. $178.3 \pm$ $25.5 \mathrm{mg} / \mathrm{dL}, p=0.43$ ). However, TG levels were significantly higher in SLE patients than in HCs $(168.9 \pm 70.1 \mathrm{mg} / \mathrm{dL}$ vs. $69.5 \pm 18.8 \mathrm{mg} / \mathrm{dL}, p<0.001)$. There was no difference between SLE patients and HCs with respect to LDL levels $(134.7 \pm 54.5 \mathrm{mg} / \mathrm{dL}$ vs. $118.3 \pm 29.9 \mathrm{mg} / \mathrm{dL}, p=0.28)$. However, HDL levels in SLE patients were significantly lower than those in $\mathrm{HCs}(21.7 \pm 9.3 \mathrm{mg} / \mathrm{dL}$ vs. $46.2 \pm$ $9.3 \mathrm{mg} / \mathrm{dL}, p<0.001$ ) (Fig. 1a). Serum cholesterol ester transfer protein (CETP) activity, which decreases HDL levels by preferentially transferring cholesterol esters from HDL to apoB-containing LDL, was higher in SLE patients than in $\mathrm{HCs}(38.4 \% \pm 6.8 \%$ vs. $34.2 \% \pm 2.6 \%$, $p=0.03$ ) (Fig. 1b).

\section{Lipoproteins from SLE patients show increased fragmentation}

The mobility of $\mathrm{HDL}_{2}, \mathrm{HDL}_{3}$, and LDL in SDS-PAGE gels was examined. The majority of $\mathrm{HDL}_{2}$ and $\mathrm{HDL}_{3}$ lipoproteins resolved as bands corresponding to the molecular weight of apoA-I $(28.3 \mathrm{kDa})$, which was then 
Table 1 Baseline demographic and clinical characteristics of the study participants

\begin{tabular}{|c|c|c|c|}
\hline & $\begin{array}{l}\text { SLE patients } \\
(\mathrm{n}=35)\end{array}$ & $\begin{array}{l}\text { Healthy controls } \\
(n=15)\end{array}$ & $p$ value \\
\hline Age, years, mean $\pm S D$ & $40.6 \pm 11.7$ & $37.7 \pm 6.1$ & 0.244 \\
\hline Female, n (\%) & $34(97.1)$ & $13(86.6)$ & 0.211 \\
\hline Height, cm & $160 . \pm 7.1^{*}$ & $161.8 \pm 6.3$ & 0.415 \\
\hline Weight, kg & $54.7 \pm 9.5^{*}$ & $53.3 \pm 6.5$ & 0.620 \\
\hline Body mass index, $\mathrm{kg} / \mathrm{m}^{2}$ & $21.3 \pm 3.1^{*}$ & $20.4 \pm 2.0$ & 0.277 \\
\hline Smoking, n (\%) & $3(9.4)$ & $0(0)$ & 0.306 \\
\hline Alcohol, n (\%) & $1(3.1)$ & $0(0)$ & 0.681 \\
\hline Diabetes, n (\%) & $2(5.7)$ & $0(0)$ & 0.486 \\
\hline Hypertension, n (\%) & $11(31.4)$ & $0(0)$ & 0.011 \\
\hline Dyslipidemia, n (\%) & $4(11.4)$ & $0(0)$ & 0.227 \\
\hline SLE duration, years & $12.1 \pm 7.6$ & & \\
\hline ESR, mm/hour & $25.4 \pm 22.5$ & & \\
\hline SLEDAI-2 K & $4.26 \pm 4.24$ & & \\
\hline C3 (mg/dL) & $75.4 \pm 23.6$ & & \\
\hline C4 (mg/dL) & $12.6 \pm 7.2$ & & \\
\hline \multicolumn{4}{|l|}{ Treatment, n (\%) } \\
\hline Corticosteroids & $35(100)$ & $0(0)$ & \\
\hline $\begin{array}{l}\text { Corticosteroid dose } \\
\text { (prednisolone equivalent), } \\
\text { mg/day }\end{array}$ & $7.8(8.4)$ & $0(0)$ & \\
\hline Hydroxychloroquine & 31 (88.6) & $0(0)$ & \\
\hline Azathioprine & $2(5.7)$ & $0(0)$ & \\
\hline Methotrexate & $1(2.9)$ & $0(0)$ & \\
\hline Statins & $2(5.7)$ & $0(0)$ & \\
\hline ACE inhibitors & $2(5.7)$ & $0(0)$ & \\
\hline ARB & $2(5.7)$ & $0(0)$ & \\
\hline Aspirin & $1(2.9)$ & $0(0)$ & \\
\hline
\end{tabular}

"Available for 32 patients

$A C E$ angiotensin-converting enzyme, $A R B$ angiotensin receptor blocker, ESR erythrocyte sedimentation rate, SLE systemic lupus erythematosus, SLEDAl-2 K, SLE disease activity index 2000

confirmed as apoA-I on Western blot analysis. The intensity of the lipoprotein bands in $\mathrm{HC}$ samples was stronger than that from SLE (Fig. 1c; left and middle panels). LDL proteins isolated from SLE patients were more fragmented than those from $\mathrm{HCs}$ (Fig. 1c; right panel, short arrows).

\section{SLE-associated lipoproteins show increased oxidation}

The increased fragility of SLE-associated lipoproteins suggests that they might have undergone additional structural modifications, such as oxidation. Therefore, we isolated $\mathrm{HDL}_{2}, \mathrm{HDL}_{3}$, and LDL from SLE patients and HCs and measured the degree of oxidation. $\mathrm{HDL}_{2}, \mathrm{HDL}_{3}$, and $\mathrm{LDL}$ from SLE patients exhibited higher levels of oxidized species than those from $\mathrm{HCs}\left(\mathrm{HDL}_{2}, 22.6 \pm 4.7\right.$ vs. $11.3 \pm 2.0$, $p<0.001 ; \mathrm{HDL}_{3}, 17.5 \pm 2.4$ vs. $7.8 \pm 1.1, p<0.001$; and LDL, $56.2 \pm 10.2$ vs. $25.4 \pm 2.3, p<0.001$ ) (Fig. 2a). Next, we examined whether lipoproteins from SLE patients were more susceptible to de novo oxidation. The oxidation rate of LDL from SLE patients (SLE-LDL) was significantly higher than LDL from $\mathrm{HCs}$ (HC-LDL) $(3.6 \% \pm 0.5 \%$ vs. $1.9 \% \pm 0.3 \%, p<0.001)$ under conditions of cupric ionmediated oxidative stress (Fig. 2b). In addition, paraoxonase activity (an HDL-associated enzyme that protects LDL from oxidation) was significantly lower in SLE patients than in HCs (3.53 \pm 0.19 vs. $4.04 \pm 0.16, p<0.001)$ (Fig. 2c).

\section{SLE-LDL induces foam cell generation and cellular senescence}

THP-1 cells (a human monocytic cell line derived from an acute monocytic leukemia) were incubated with LDL isolated from SLE patients or HCs. THP-1 cells phagocytosed significantly more SLE-LDL than HC-LDL (NBD positive area: $2501 \pm 401.2$ vs. $524.1 \pm 59.9$ arbitrary units (AUs), $p<0.001$ ) and transformed into foam cells (Fig. 3a and b). Exposure of human fibroblasts to SLE-LDL induced accelerated cellular senescence, as reflected by increased $\beta$-galactosidase activity $(70.9 \pm 17.9$ vs. $16.3 \pm 2.4$, $p<0.001$ ) (Fig. 3c and d).

\section{SLE lipoproteins cause oxidative stress in zebrafish embryos}

Zebrafish embryos were injected with LDL isolated from SLE patients or HCs. SLE-LDL induced significantly higher levels of DHE oxidation in vivo than HC-LDL $(1592.0 \pm 58.7$ AUs vs. $459.6 \pm 66.4$ AUs, $p<0.001)$ (Fig. 4a and b). Next, embryos were injected with oxLDL in the presence of anti-oxidative $\mathrm{HDL}_{3}$ isolated from SLE patients or HCs. Embryos exposed to oxLDL alone showed marked oxidation of DHE (Fig. 4c; left panel). Co-injection of $\mathrm{HDL}_{3}$ from $\mathrm{HCs}$ or SLE patients reduced DHE oxidation than oxLDL alone (both $p<0.001$ ). However, $\mathrm{HDL}_{3}$ from SLE patients induced significantly more DHE oxidation than that from HCs $(3358 \pm 208.8$ AUs vs. $1299 \pm 75.1$ AUs, $p<0.001$ ) (Fig. 4 d).

SLE-LDL was toxic to embryos: 8 hours after injection, $68.3 \% \pm 3.0 \%$ of embryos exposed to SLE-LDL remained alive compared with $94.6 \% \pm 1.1 \%$ exposed to HC-LDL. After 48 hours, the mean survival rate of SLE-LDLexposed embryos was $49.3 \% \pm 2.8 \%$ whereas that of HC-LDL-exposed embryos was $85.0 \% \pm 2.9 \%(p<0.001)$ (Fig. 4e). The injection of oxidized LDL purified from HCs reduced the embryo survival to $48.6 \%$ after 48 hours. The toxicity of oxLDL was partially reversed or neutralized by co-injection of protective HDLs: co-injection of $\mathrm{HDL}_{3}$ from $\mathrm{HCs}$ improved the embryo survival as compared to $\mathrm{HDL}_{3}$ from SLE patients $(75.1 \% \pm$ $2.1 \%$ vs. $62.0 \% \pm 3.1 \%, p<0.001$ ) (Fig. 4 f). 


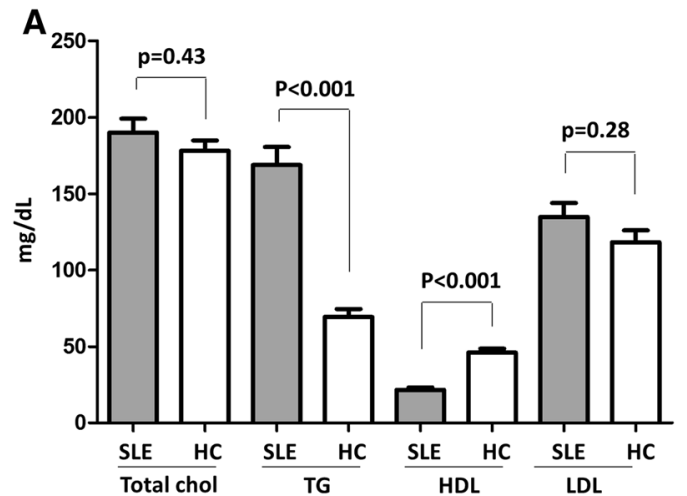

C

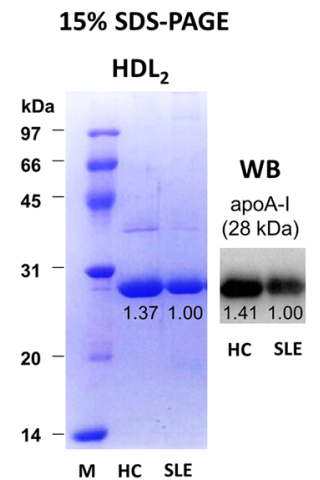

B
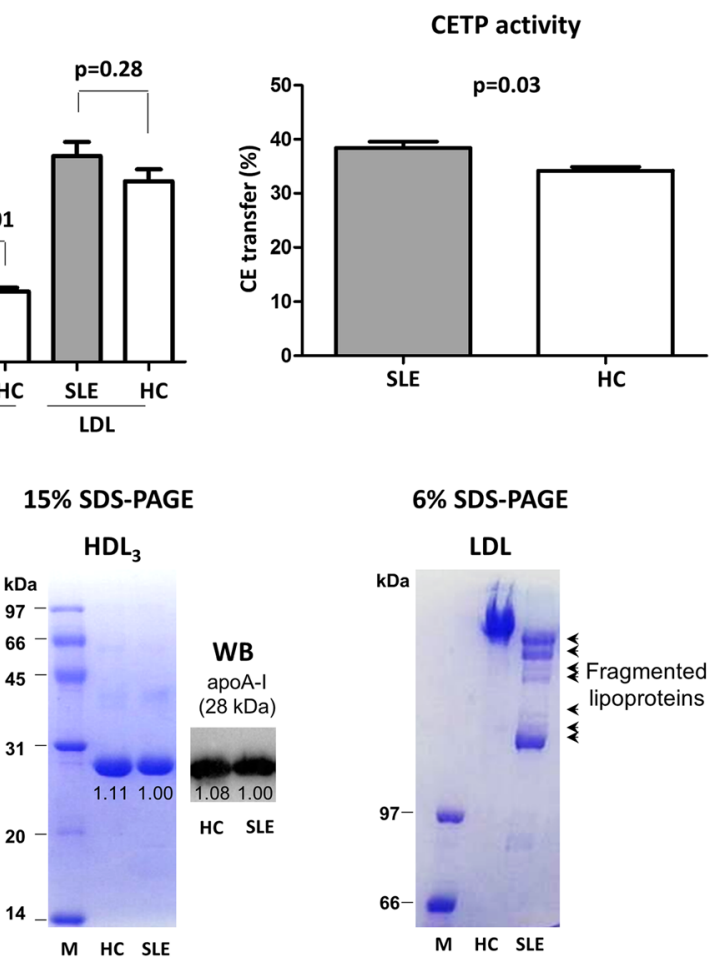

6\% SDS-PAGE

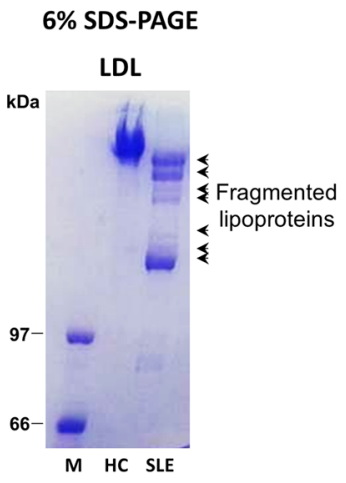

Fig. 1 Comparison of serum lipid profile between SLE patients and heathy controls. a Fasting levels of total cholesterol, triglyceride (TG), HDL, and LDL were compared between SLE patients $(n=35)$ and HCs $(n=15)$. SLE patients had higher levels of TG and lower levels of HDL than HCs. $\mathbf{b}$ The serum activity of CETP was significantly higher in SLE patients than in HCs. c Equivalent amounts of $H_{2} L_{2}, H D L_{3}$, and LDL pooled from SLE $(n=19)$ patients and $\mathrm{HCs}(\mathrm{n}=8)$ were subjected to SDS-PAGE ( $6 \%$ gels for $\mathrm{HDL}_{2}$ and $\mathrm{HDL}_{3}$ and $15 \%$ gels for $\mathrm{LDL}$ ). $\mathrm{HDL}_{2}$ and $\mathrm{HDL}_{3}$ ran as a single band which was identified as apoA-I on Western blot (WB). The intensity of the band of apoA-I was weaker in SLE samples than in HC samples (left and middle panels). The proteins derived from SLE-LDL ran as multiple fragments (right panel, arrow), whereas HC-LDL ran as a single band. The numbers under the bands represent the relative band intensity whereas the intensity of SLE bands was set as 1.00). Results are representative of three independent experiments. Data are expressed as the mean and SEM. CETP cholesterol ester transfer protein, M markers, HC healthy control, SLE systemic lupus erythematosus

\section{Discussion}

Increased generation of oxLDL is crucial for the pathogenesis of atherosclerosis: oxLDL accumulates in vascular walls and attracts monocytes, which then differentiate into tissue macrophages and release inflammatory cytokines [29]. Foam cells within the vessel wall form the lipid core of an atherosclerotic plaque [30-32]. Furthermore, oxLDL induces cellular senescence, impairs endothelial cell function, and inhibits the release of protective nitric oxide [33,34]. Accordingly, because statins make LDL less available for oxidation by reducing the hepatic synthesis of cholesterol (which is the main lipid component of LDL) [35], they lead to a significant reduction in CV-related mortality in the general population [36]. However, atorvastatin did not inhibit or reverse the atherosclerosis in patients with SLE, although it reduced LDL levels [10]. This suggests that not only the quantity but also the quality of lipoproteins might, at least in part, account for the non-traditional risk factors for accelerated atherosclerosis in SLE patients.
Here, we provide direct evidence that circulating lipoproteins in patients with SLE are altered and show specific physicochemical properties. First, SLE-LDL exhibited greater oxidation and fragility than HC-LDL. Second, SLE-LDL was more susceptible to de novo oxidation. Third, SLE-LDL induced foam cells and accelerated cellular senescence. Fourth, injection of SLE-LDL into zebrafish embryos caused greater oxidative stress and higher embryonic mortality. Finally, HDL from SLE patients had impaired anti-oxidative and protective effects. In short, lipoproteins from SLE patients showed higher oxidative and lower anti-oxidative potential than lipoproteins from HCs with detrimental physiological effects.

Serum lipoproteins are produced by the liver. During acute systemic inflammation, inflammatory cytokines increase the hepatic production of acute phase reactants. The levels of serum amyloid protein (SAA), an apolipoprotein associated with HDL [37], increase during active inflammation, as occurs during active SLE [16]. Thus, the SAA content of HDL increases at the expense of 

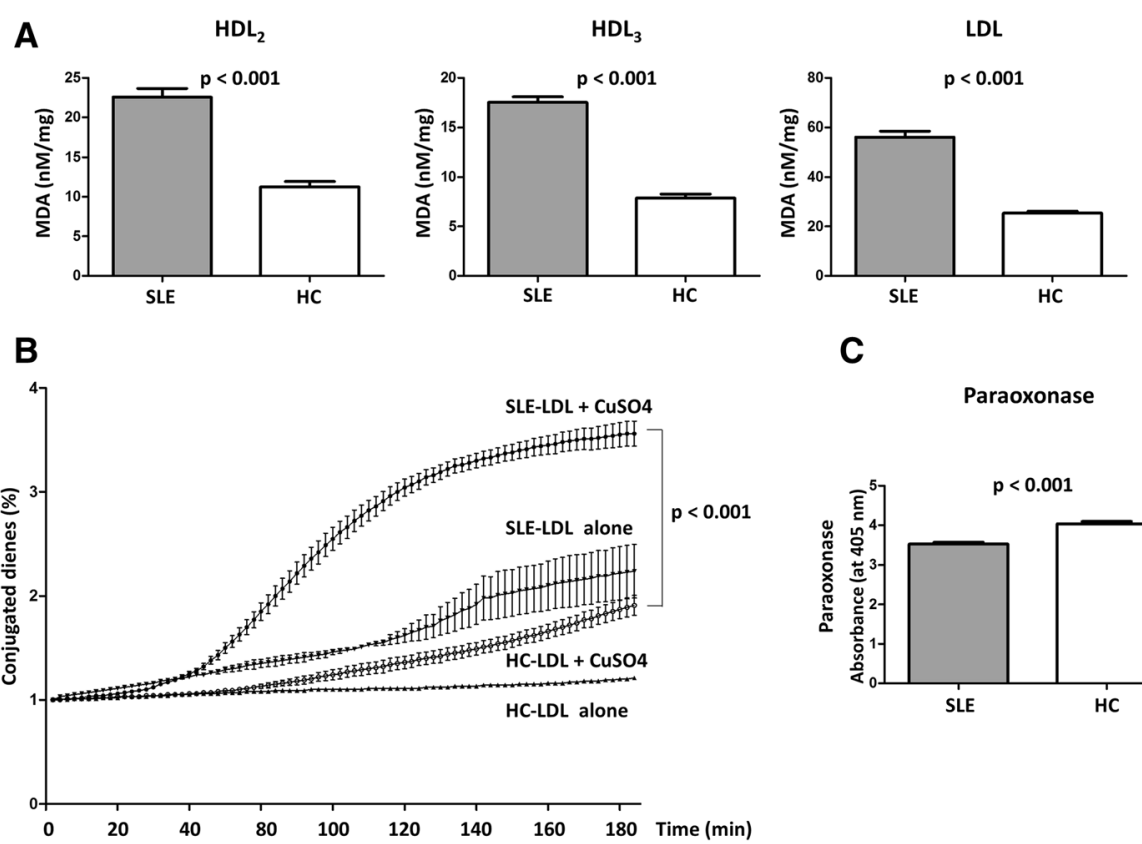

C

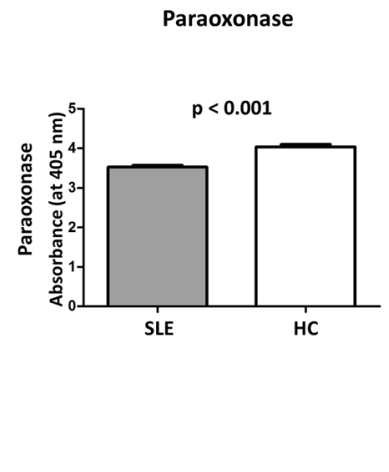

Fig. 2 Increased oxidation of lipoproteins from systemic lupus erythematosus (SLE) patients. a $H D L_{2}, H D L_{3}$, and LDL were isolated from SLE patients $(n=19)$ and healthy controls (HCs) $(n=8)$, and their oxidation status (i.e., MDA levels) was measured. All lipoprotein fractions from SLE patients showed significantly higher levels of oxidation than those from HCs. $\mathbf{b} \mathrm{LDL}$ was incubated in the presence of $5 \mu \mathrm{M} \mathrm{CuSO}_{4}$, and the formation of conjugated dienes over time was measured as a marker of de novo oxidation. LDL from SLE patients was significantly more susceptible to oxidation than that from HCs. c Serum paraoxonase activity was significantly lower in SLE samples than in HC samples. Data are expressed as the mean and SEM. HC healthy controls, MDA malondialdehyde, SLE systemic lupus erythematosus

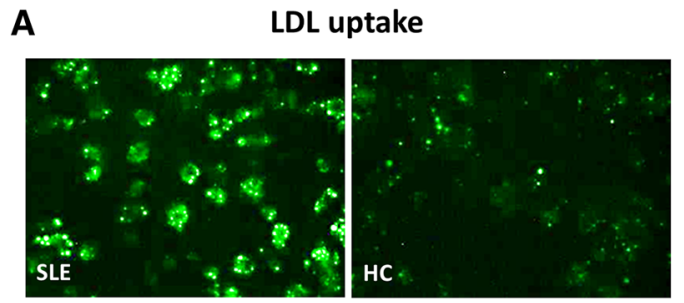

C

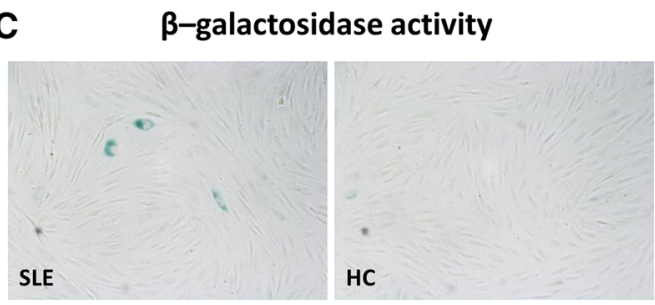

B

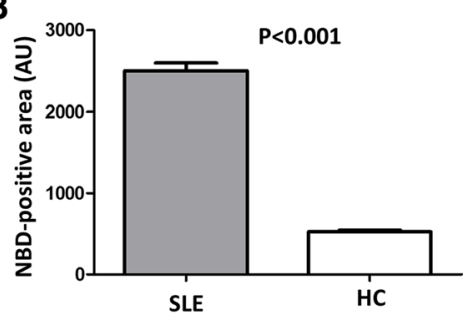

D

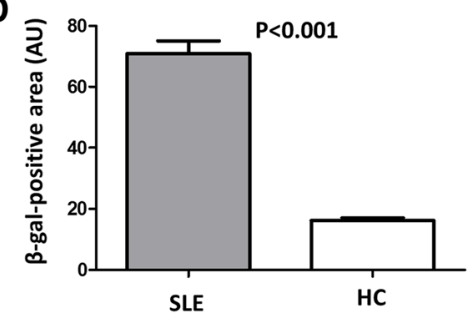

Fig. 3 Monocytes show increased uptake of LDL from SLE patients. $\mathbf{a}$ and $\mathbf{b}$ THP-1 cells were incubated with LDL isolated from SLE patients ( $\mathrm{n}=19)$ and HCS $(n=8)$. THP-1 cells phagocytosed significantly more LDL from SLE patients and showed greater foam cell formation (NBD-positive area: $2501 \pm 401.2$ AUs vs. $524.1 \pm 59.9$ AUs, respectively; $p<0.001$ ). c Human fibroblast cells were incubated with LDL from SLE patients or HCs, and $\beta$-galactosidase activity (a surrogate marker for cellular senescence) was measured. $\beta$-galactosidase activity was higher in fibroblasts treated with SLE-LDL (blue) than in those treated with HC-LDL. d SLE-LDL induced significantly higher $\beta$-galactosidase activity than HC-LDL ( $\beta$-gal positive area: 70.9 AUs vs. 16.3 AUs, respectively; $p<0.001$ ). Representative images ( $\times 400$ magnification) from at least three independent experiments are shown. Data are expressed as the mean and SEM. AU arbitrary units, gal galactosidase, HC healthy control, MDA malondialdehyde, NBD 22-(N-7-nitrobenz-2-oxa-1,3-diazol-4-yl) amino-23, 24-bisnor-5-cholen3-ol, SLE systemic lupus erythematosus 

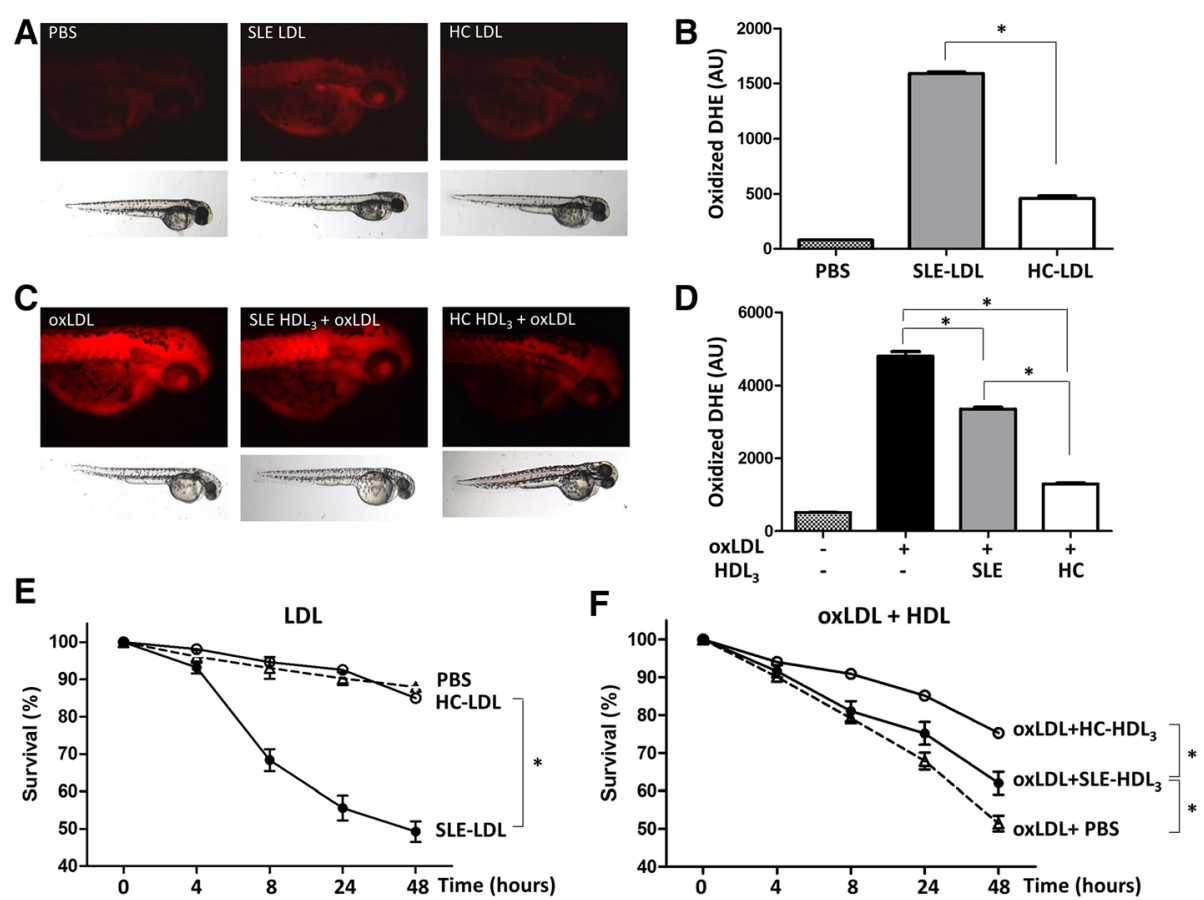

Fig. 4 LDL from SLE patients induces oxidative stress in vivo. a Zebrafish embryos were injected with LDL from SLE patients $(n=19)$ or HCS $(n=8)$, and oxidation of dihydroethidium (DHE, bright red; a surrogate marker for reactive oxygen species production) was observed under a fluorescence microscope. The embryos injected with SLE-LDL showed increased fluorescence compared with those treated with PBS or HC-LDL. b SLE-LDL induced significantly more oxidation than HC-LDL. c The embryos injected with oxLDL alone showed strong fluorescence, which was reduced upon co-injection of $\mathrm{HDL}_{3}$ from HCs or SLE patients. $\mathbf{d} \mathrm{HDL}_{3}$ from SLE patients induced significantly more DHE oxidation than that from HCs. e Injection of SLE-LDL reduced the embryo survival to a greater extent than HC-LDL or PBS. $\mathbf{f}$ The embryos treated with purified oxLDL showed a markedly reduced survival rate after 48 hours. $H D L_{3}$ from SLE patients and HCs increased the survival of embryos treated with oxLDL. HC-HDL 3 improved the survival to a greater extent than SLE-HLD . Data are expressed as the mean and SEM ( $p<0.001)$. AU arbitrary units, DHE dihydroethidium, HC healthy control, MDA malondialdehyde, SLE systemic lupus erythematosus

apoA-I; this impairs the reverse cholesterol transport of HDL [38]. Here, we found that the proportion of apoA-I in $\mathrm{HDL}_{2}$ and $\mathrm{HDL}_{3}$ from SLE patients seemed to be lower than that in $\mathrm{HDL}_{2}$ and $\mathrm{HDL}_{3}$ from HCs (Fig. 1c). Also, LDL from SLE patients was more fragile and more susceptible to oxidation (Fig. 2). Reduced paraoxonase activity, which protects LDL from oxidative modification, might potentiate the generation of oxLDL in SLE [17]. Taken together, HDL dysfunction (possibly due to altered composition), reduced paraoxonase activity, and increased susceptibility of LDL to oxidation might all contribute to increased generation of oxLDL. Consistent with increased LDL oxidation, we found that THP-1 cells readily engulfed SLE-LDL and transformed into foam cells (Fig. 3). Since monocytes from SLE are the same as those from HCs in terms of their capacity to take up oxLDL and transform into foam cells [39], the increased phagocytosis of SLE-LDL is likely due to SLEspecific alterations in structure/function of lipoproteins.

To the best of our knowledge, this study is the first to show that LDL from SLE patients exhibits deleterious oxidative effects in vivo using zebrafish embryos. Zebrafish embryo is suitable to study in vivo oxidation, since their optical clarity allows dynamic tracking of the oxidation process using a fluorescence probe [40]. Further studies are needed to show whether the alteration of lipoproteins can be translated into accelerated atherosclerosis in vivo as well.

It is not clear whether the findings observed herein are SLE-specific or are generalizable to other chronic inflammatory diseases such as rheumatoid arthritis and primary systemic vasculitis, both of which are associated with an increased risk of CV-related morbidity [41]. Since even a slight increase in CRP levels is associated with increased CV-related morbidity, one might speculate that smoldering inflammation in general might be associated with alterations in the properties of lipoproteins $[42,43]$. The finding that anti-oxidant vitamins did not prevent atherosclerosis raises the question of whether the detrimental effects of oxidized lipoproteins are irreversible [44]. Tight control of SLE disease activity and the associated systemic inflammation, might reduce $\mathrm{CV}$ risk as seen in patients with rheumatoid arthritis [45].

The present study has several limitations. First, the HCs were not matched for all comorbidities. Second, the relatively small number of SLE patients does not allow 
to assess the effects of medical treatment, particularly those of corticosteroids, hydroxychloroquine, and statins, which could have pleiotropic effects on lipid metabolism [46]. Third, since the lipid oxidation can occur during storage, the possible impact of the storage time on the degree of spontaneous lipid oxidation needs further investigation. Fourth, due to a technical limitation, the protein fragments in the SLE-LDL could not be unequivocally identified as apolipoproteins. Fifth, it might be of interest to examine changes in the physicochemical properties of lipoproteins in treated SLE patients over time. Ultimately, further studies should determine whether the findings of the present study can be translated into an in vivo model of accelerated atherosclerosis.

\section{Conclusions}

Lipoproteins from SLE patients show altered structural and functional properties with higher oxidative potential in vitro and in vivo. Further studies should examine whether alterations in lipoproteins directly contribute to the accelerated atherosclerosis associated with SLE.

\section{Additional file}

Additional file 1: Table S1. Baseline demographic and clinical

characteristics of the participants included in the pooled samples. Figure

S1. Age distribution of 19 systemic lupus erythematosus (SLE) patients and 8 healthy controls ( $\mathrm{HCs}$ ) included in the pooled samples. (PDF $222 \mathrm{~kb}$ )

\section{Abbreviations}

CE: cholesteryl ester; CEPT: cholesterol ester transfer protein; CRP: C-reactive protein; CV: cardiovascular; DHE: dihydroethidium; HC: healthy control; HDL: high-density lipoprotein; LDL: low-density lipoprotein; MDA: malondialdehyde; oxLDL: oxidized LDL; rHDL: recombinant $\mathrm{HDL}$; SA: senescence-associated; SAA: serum amyloid protein; SDS-PAGE: sodium dodecyl sulfate-polyacrylamide gel electrophoresis; SLE: systemic lupus erythematosus; SLEDAl: SLE disease activity index; TG: triglyceride

\section{Acknowledgements}

Not applicable.

\section{Funding}

This work was supported by a grant from the Korea Health Technology R\&D Project through the Korea Health Industry Development Institute funded by the Ministry of Health and Welfare, Republic of Korea (grant number: HI13C1754) and by a grant from the Mid-carrier Researcher Program (2014-11049455) through the National Research Foundation funded by the Ministry of Science, ICT, and Future Planning, Republic of Korea.

\section{Availability of data and materials}

Not applicable.

\section{Authors' contributions}

JKP and YWS conceived the study, analyzed and interpreted data, and participated in drafting the manuscript. JYK, JYM, EYA, EYL, EBL, and KHC made substantial contributions to data analysis, data interpretation, and drafting of the manuscript. All authors read and approved the final manuscript.

\section{Authors' information}

Not applicable.

\section{Competing interests}

The authors declare that they have no competing interests.

\section{Consent for publication}

Not applicable.

\section{Ethical approval and consent to participate}

Informed consent was obtained from all participants in accordance with the Declaration of Helsinki. The study was approved by the Institutional Review Board at Seoul National University Hospital.

\section{Author details}

${ }^{1}$ Department of Molecular Medicine and Biopharmaceutical Sciences, Graduate School of Convergence Science and Technology, and College of Medicine, Medical Research Center, Seoul National University, Seoul, Republic of Korea. 'Division of Rheumatology, Department of Internal Medicine, Seoul National University Hospital, Seoul, Republic of Korea. ${ }^{3}$ Department of Medical Biotechnology, Yeungnam University, Gyeongsangbuk-Do, Republic of Korea. ${ }^{4}$ Division of Rheumatology, Department of Internal Medicine, Seoul National University College of Medicine, 101 Daehak-ro, Jongno-gu, Seoul 03080, Republic of Korea.

Received: 5 July 2016 Accepted: 5 December 2016

Published online: 30 December 2016

\section{References}

1. Liu Z, Davidson A. Taming lupus-a new understanding of pathogenesis is leading to clinical advances. Nat Med. 2012;18(6):871-82.

2. Manzi S, Meilahn EN, Rairie JE, Conte CG, Medsger Jr TA, Jansen-McWilliams L, D'Agostino RB, Kuller LH. Age-specific incidence rates of myocardial infarction and angina in women with systemic lupus erythematosus: comparison with the Framingham Study. Am J Epidemiol. 1997;145(5):408-15.

3. Bessant R, Hingorani A, Patel L, MacGregor A, Isenberg DA, Rahman A. Risk of coronary heart disease and stroke in a large British cohort of patients with systemic lupus erythematosus. Rheumatology (Oxford). 2004;43(7):924-9.

4. Bruce IN, Urowitz MB, Gladman DD, Ibanez D, Steiner G. Risk factors for coronary heart disease in women with systemic lupus erythematosus: the Toronto Risk Factor Study. Arthritis Rheum. 2003;48(11):3159-67.

5. Chung CP, Avalos I, Oeser A, Gebretsadik T, Shintani A, Raggi P, Michael SC. High prevalence of the metabolic syndrome in patients with systemic lupus erythematosus: association with disease characteristics and cardiovascular risk factors. Ann Rheum Dis. 2007:66(2):208-14.

6. Esdaile JM, Abrahamowicz M, Grodzicky T, Li Y, Panaritis C, du Berger R, Cote $\mathrm{R}$, Grover SA, Fortin PR, Clarke AE, et al. Traditional Framingham risk factors fail to fully account for accelerated atherosclerosis in systemic lupus erythematosus. Arthritis Rheum. 2001:44(10):2331-7.

7. Magder LS, Petri M. Incidence of and risk factors for adverse cardiovascular events among patients with systemic lupus erythematosus. Am J Epidemiol. 2012;176(8):708-19.

8. Roman MJ, Shanker BA, Davis A, Lockshin MD, Sammaritano L, Simantov R, Crow MK, Schwartz JE, Paget SA, Devereux RB, et al. Prevalence and correlates of accelerated atherosclerosis in systemic lupus erythematosus. N Engl J Med. 2003;349(25):2399-406.

9. Lee AB, Godfrey T, Rowley KG, Karschimkus CS, Dragicevic G, Romas E, Clemens L, Wilson AM, Nikpour M, Prior DL, et al. Traditional risk factor assessment does not capture the extent of cardiovascular risk in systemic lupus erythematosus. Intern Med J. 2006:36(4):237-43.

10. Petri MA, Kiani AN, Post W, Christopher-Stine L, Magder LS. Lupus Atherosclerosis Prevention Study (LAPS). Ann Rheum Dis. 2011;70(5):760-5.

11. Schanberg LE, Sandborg C, Barnhart HX, Ardoin SP, Yow E, Evans GW, Mieszkalski KL, llowite NT, Eberhard A, Imundo LF, et al. Use of atorvastatin in systemic lupus erythematosus in children and adolescents. Arthritis Rheum. 2012:64(1):285-96.

12. Navab M, Hama SY, Anantharamaiah GM, Hassan K, Hough GP, Watson AD, Reddy ST, Sevanian A, Fonarow GC, Fogelman AM. Normal high density lipoprotein inhibits three steps in the formation of mildly oxidized low density lipoprotein: steps 2 and 3. J Lipid Res. 2000;41(9):1495-508.

13. Navab M, Hama SY, Cooke CJ, Anantharamaiah GM, Chaddha M, Jin L, Subbanagounder G, Faull KF, Reddy ST, Miller NE, et al. Normal high density lipoprotein inhibits three steps in the formation of mildly oxidized low density lipoprotein: step 1. J Lipid Res. 2000;41(9):1481-94. 
14. Navab M, Berliner JA, Watson AD, Hama SY, Territo MC, Lusis AJ, Shih DM, Van Lenten BJ, Frank JS, Demer LL, et al. The Yin and Yang of oxidation in the development of the fatty streak. A review based on the 1994 George Lyman Duff Memorial Lecture. Arterioscler Thromb Vasc Biol. 1996;16(7):831-42

15. Smith CK, Seto NL, Vivekanandan-Giri A, Yuan W, Playford MP, Manna Z, Hasni SA, Kuai R, Mehta NN, Schwendeman A, et al. Lupus high-density lipoprotein induces proinflammatory responses in macrophages by binding lectin-like oxidised low-density lipoprotein receptor 1 and failing to promote activating transcription factor 3 activity. Ann Rheum Dis. 2016; 209683. [Epub ahead of print].

16. McMahon M, Grossman J, FitzGerald J, Dahlin-Lee E, Wallace DJ, Thong BY, Badsha H, Kalunian K, Charles C, Navab M, et al. Proinflammatory high-density lipoprotein as a biomarker for atherosclerosis in patients with systemic lupus erythematosus and rheumatoid arthritis. Arthritis Rheum. 2006;54(8):2541-9.

17. Van Lenten BJ, Wagner AC, Nayak DP, Hama S, Navab M, Fogelman AM. High-density lipoprotein loses its anti-inflammatory properties during acute influenza a infection. Circulation. 2001;103(18):2283-8.

18. Okura Y, Brink M, Itabe H, Scheidegger KJ, Kalangos A, Delafontaine P. Oxidized low-density lipoprotein is associated with apoptosis of vascular smooth muscle cells in human atherosclerotic plaques. Circulation. 2000;102(22):2680-6.

19. Podrez EA, Poliakov E, Shen Z, Zhang R, Deng Y, Sun M, Finton PJ, Shan L, Gugiu B, Fox PL, et al. Identification of a novel family of oxidized phospholipids that serve as ligands for the macrophage scavenger receptor CD36. J Biol Chem. 2002;277(41):38503-16.

20. Miller Yl, Chang MK, Binder CJ, Shaw PX, Witztum JL. Oxidized low density lipoprotein and innate immune receptors. Curr Opin Lipidol. 2003;14(5):437-45.

21. Hochberg MC. Updating the American College of Rheumatology revised criteria for the classification of systemic lupus erythematosus. Arthritis Rheum. 1997;40(9):1725.

22. Gladman DD, Ibanez D, Urowitz MB. Systemic lupus erythematosus disease activity index 2000. J Rheumatol. 2002;29(2):288-91.

23. Havel RJ, Eder HA, Bragdon JH. The distribution and chemical composition of ultracentrifugally separated lipoproteins in human serum. J Clin Invest. 1955;34(9):1345-53.

24. Markwell MA, Haas SM, Bieber LL, Tolbert NE. A modification of the Lowry procedure to simplify protein determination in membrane and lipoprotein samples. Anal Biochem. 1978;87(1):206-10.

25. Blois MS. Antioxidant determinations by the use of a stable free radical. Nature. 1958;181:1199-200.

26. Cho KH. Synthesis of reconstituted high density lipoprotein (rHDL) containing apoA-I and apoC-III: the functional role of apoC-III in $\mathrm{rHDL}$. Mol Cells. 2009;27(3):291-7.

27. Cho KH, Shin DG, Baek SH, Kim JR. Myocardial infarction patients show altered lipoprotein properties and functions when compared with stable angina pectoris patients. Exp Mol Med. 2009;41(2):67-76.

28. Park KH, Shin DG, Kim JR, Hong JH, Cho KH. The functional and compositional properties of lipoproteins are altered in patients with metabolic syndrome with increased cholesteryl ester transfer protein activity. Int J Mol Med. 2010;25(1):129-36.

29. Levitan I, Volkov S, Subbaiah PV. Oxidized LDL: diversity, patterns of recognition, and pathophysiology. Antioxid Redox Signal. 2010;13(1):39-75.

30. McMahon M, Skaggs BJ, Grossman JM, Sahakian L, Fitzgerald J, Wong WK, Lourenco EV, Ragavendra N, Charles-Schoeman C, Gorn A, et al. A panel of biomarkers is associated with increased risk of the presence and progression of atherosclerosis in women with systemic lupus erythematosus. Arthritis Rheumatol. 2014;66(1):130-9.

31. Frostegard J, Svenungsson E, Wu R, Gunnarsson I, Lundberg IE, Klareskog L, Horkko S, Witztum JL. Lipid peroxidation is enhanced in patients with systemic lupus erythematosus and is associated with arterial and renal disease manifestations. Arthritis Rheum. 2005;52(1):192-200.

32. Svenungsson E, Jensen-Urstad K, Heimburger M, Silveira A, Hamsten A, de Faire U, Witztum JL, Frostegard J. Risk factors for cardiovascular disease in systemic lupus erythematosus. Circulation. 2001;104(16):1887-93.

33. Chin JH, Azhar S, Hoffman BB. Inactivation of endothelial derived relaxing factor by oxidized lipoproteins. J Clin Invest. 1992;89(1):10-8.

34. Vink H, Constantinescu AA, Spaan JA. Oxidized lipoproteins degrade the endothelial surface layer : implications for platelet-endothelial cell adhesion. Circulation. 2000:101(13):1500-2.
35. Davignon J. Beneficial cardiovascular pleiotropic effects of statins. Circulation. 2004;109(23 Suppl 1):III39-43.

36. Stone NJ, Robinson JG, Lichtenstein AH, Bairey Merz CN, Blum CB, Eckel RH, Goldberg AC, Gordon D, Levy D, Lloyd-Jones DM, et al. 2013 ACC/AHA guideline on the treatment of blood cholesterol to reduce atherosclerotic cardiovascular risk in adults: a report of the American College of Cardiology/ American Heart Association Task Force on Practice Guidelines. Circulation. 2014;129(25 Suppl 2):S1-45.

37. Kisilevsky R, Manley PN. Acute-phase serum amyloid A: perspectives on its physiological and pathological roles. Amyloid. 2012;19(1):5-14.

38. Daynes RA, Jones DC. Emerging roles of PPARs in inflammation and immunity. Nat Rev Immunol. 2002;2(10):748-59.

39. Yassin LM, Londono J, Montoya G, De Sanctis JB, Rojas M, Ramirez LA, Garcia LF, Vasquez G. Atherosclerosis development in SLE patients is not determined by monocytes ability to bind/endocytose Ox-LDL. Autoimmunity. 2011;44(3):201-10.

40. Mugoni V, Camporeale A, Santoro MM. Analysis of oxidative stress in zebrafish embryos. J Vis Exp. 2014;(89).

41. Prasad M, Hermann J, Gabriel SE, Weyand CM, Mulvagh S, Mankad R, Oh JK, Matteson EL, Lerman A. Cardiorheumatology: cardiac involvement in systemic rheumatic disease. Nat Rev Cardiol. 2015;12(3):168-76.

42. Ridker PM, Rifai N, Pfeffer MA, Sacks FM, Moye LA, Goldman S, Flaker GC, Braunwald E. Inflammation, pravastatin, and the risk of coronary events after myocardial infarction in patients with average cholesterol levels. Cholesterol and Recurrent Events (CARE) Investigators. Circulation. 1998;98(9):839-44.

43. Sattar N, Murray HM, Welsh P, Blauw GJ, Buckley BM, Cobbe S, de Craen AJ, Lowe GD, Jukema JW, Macfarlane PW, et al. Are markers of inflammation more strongly associated with risk for fatal than for nonfatal vascular events? PLoS Med. 2009;6(6):e1000099.

44. Vivekananthan DP, Penn MS, Sapp SK, Hsu A, Topol EJ. Use of antioxidant vitamins for the prevention of cardiovascular disease: meta-analysis of randomised trials. Lancet. 2003;361(9374):2017-23.

45. Ljung L, Rantapaa-Dahlqvist S, Jacobsson LT, Askling J, Group AS. Response to biological treatment and subsequent risk of coronary events in rheumatoid arthritis. Ann Rheum Dis. 2016:75(12):2087-94.

46. Ansell BJ, Navab M, Hama S, Kamranpour N, Fonarow G, Hough G, Rahmani S, Mottahedeh R, Dave R, Reddy ST, et al. Inflammatory/antiinflammatory properties of high-density lipoprotein distinguish patients from control subjects better than high-density lipoprotein cholesterol levels and are favorably affected by simvastatin treatment. Circulation. 2003;108(22):2751-6.

\section{Submit your next manuscript to BioMed Central and we will help you at every step:}

- We accept pre-submission inquiries

- Our selector tool helps you to find the most relevant journal

- We provide round the clock customer support

- Convenient online submission

- Thorough peer review

- Inclusion in PubMed and all major indexing services

- Maximum visibility for your research

Submit your manuscript at www.biomedcentral.com/submit
) Biomed Central 